\title{
Brain HIV-1 latently-infected reservoirs targeted by the suicide gene strategy
}

\author{
Sepideh Saeb 1,2, Mehrdad Ravanshad ${ }^{1 *}$, Mahmoud Reza Pourkarim³ ${ }^{3}$ Fadoua Daouad², Kazem Baesi ${ }^{4}$, \\ Olivier Rohr ${ }^{2}$, Clémentine Wallet ${ }^{2 \dagger}$ and Christian Schwartz ${ }^{2 *}$
}

\begin{abstract}
Reducing the pool of HIV-1 reservoirs in patients is a must to achieve functional cure. The most prominent HIV-1 cell reservoirs are resting CD4 $+T$ cells and brain derived microglial cells. Infected microglial cells are believed to be the source of peripheral tissues reseedings and the emergence of drug resistance. Clearing infected cells from the brain is therefore crucial. However, many characteristics of microglial cells and the central nervous system make extremely difficult their eradication from brain reservoirs. Current methods, such as the "shock and kill", the "block and lock" and gene editing strategies cannot override these difficulties. Therefore, new strategies have to be designed when considering the elimination of brain reservoirs. We set up an original gene suicide strategy using latently infected microglial cells as model cells. In this paper we provide proof of concept of this strategy.
\end{abstract}

Keywords: HIV-1, Microglial, Latent reservoirs, Suicide gene

\section{Introduction}

Since the introduction of the combination antiretroviral therapy (cART) in 1996 the lethal HIV-1 infection has evolved to become a chronic disease. However, despite continual efforts definitive cure has not been achieved principally due to the existence of latently-infected HIV-1 reservoirs. Resting CD4 $+\mathrm{T}$ cells are known to be the principal reservoir of HIV but we have now abundant proofs that many other cell reservoirs such as hematopoietic stem cells, dendritic cells, microglial cells and cells from the monocyte-macrophage lineage (reviewed in [13]) exist. Furthermore, some of these reservoirs are found in sanctuaries such as the genital tract, the adipose tissue, the bone marrow or in the brain.

\footnotetext{
*Correspondence: Ravanshad@modares.ac.ir; schwartz.christian@unistra.fr ${ }^{\dagger}$ Clémentine Wallet and Christian Schwartz have contributed equally to this work

${ }^{1}$ Department of Virology, Faculty of Medical Sciences, Tarbiat Modares University, Tehran, Iran

2 University of Strasbourg, Research Unit 7292, DHPI, IUT Louis Pasteur, Schiltigheim, France

Full list of author information is available at the end of the article
}

A prerequisite to successfully purge reservoirs is to understand the molecular mechanisms involved in the establishment and maintenance of HIV-1 latency. Understanding these mechanisms could help to identify new target proteins in the viral cycle, which are not affected by cART [4]. Some of these molecular mechanisms are known. We have notably shown that the cellular cofactor CTIP2 (Bcl11b) supports both the establishment and the maintenance of HIV-1 post-integration latency in microglial cells [5-7]. CTIP2 works as a scaffold protein by recruiting at least two different complexes in microglial cells. As part of a chromatin remodelling complex CTIP2 is associated with the lysine demethylase LSD1, the histone deacetylases HDAC1 and HDAC2, and the histone methyltransferase SUV39H1[5, 8-10]. CTIP2 is also involved in the control of the elongation process of gene transcription by inhibiting P-TEFb functions. [11, 12].

To date, three strategies are considered to eliminate reservoirs: 1) the "Shock and Kill", 2) the alternative "Block and Lock" and 3) gene therapy including the gene editing based strategy. The "Shock and Kill" strategy is based on the reactivation of the latent virus followed by original author(s) and the source, provide a link to the Creative Commons licence, and indicate if changes were made. The images or other third party material in this article are included in the article's Creative Commons licence, unless indicated otherwise in a credit line to the material. If material is not included in the article's Creative Commons licence and your intended use is not permitted by statutory regulation or exceeds the permitted use, you will need to obtain permission directly from the copyright holder. To view a copy of this licence, visit http://creativecommons.org/licenses/by/4.0/. The Creative Commons Public Domain Dedication waiver (http://creativeco mmons.org/publicdomain/zero/1.0/) applies to the data made available in this article, unless otherwise stated in a credit line to the data. 
the intensification of cART, which eliminate reactivated viruses. This strategy seeks to achieve clearance of the reservoirs either by a cytopathic effect on the reactivated virus or inducing the immune system via the actions of cytotoxic T cells (CTLs) [13]. The "Shock and Kill" strategy today is only conceivable with circulating reservoirs such as the resting $\mathrm{T}$ CD4+ cells. Indeed, targeting the brain reservoirs with the "Shock and Kill" strategy is not feasible due to several characteristics of the central nervous system (CNS):

i. The CNS has barriers (the Brain Blood Barrier and the choroid plexus) which lower the penetration of drugs into the brain [14].

ii. The main cellular targets of cART are CNS resident macrophages including perivascular macrophages and microglial cells. However, few drugs are able to target the monocyte-macrophages lineage and microglial cells [15].

iii. Reactivation of the virus with Latency Reversing Agents (LRAs) leads to the synthesis of neurotoxic viral proteins such as Tat, Vpr and the gp120. Furthermore, reactivation of the virus activates macrophage/microglial cells and it is often correlated with CNS inflammation [16,17].

An alternative approach to achieve long term control of HIV-1 in the absence of cART is to induce long lasting inhibition of HIV-1 gene expression [18]. Molecules inhibiting HIV-1 expression, called latency-promoting agents (LPAs), induce deep latency state (the Block) and prevent HIV-1 gene transcription (the Lock) [19]. Among LPAs, didehydro-corticostatin (dCA), an inhibitor of the transactivor Tat, had promising effect. However, a recent in vitro study described virus resistance to this agent [20]. Recently introduced gene therapies show promising results as well. The gene therapy targeting CCR5 co-receptor aims to replace wild type receptor by bone marrow transplantation of stem cells harboring CCR 5 deletion mutation [21]. Stem-cells carrying a CCR5 $\Delta 32$ mutation confers resistance to HIV infection.

Mutational inactivation of HIV-1 by the gene editing CRISPR/Cas9 technique to disrupt the HIV genome is also promising [22]. Unfortunately, a major off-target of the gene editing strategy is the rise of unwanted gene mutations and chromosomal translocations [23]. Indeed, preliminary results of gene editing trials using CRISPR/ Cas9 technique [24] showed that the virus was able to subvert the DNA repair machinery to rapidly evolve into CRISPR/Cas9 resistant strains [25-28]. In order to circumvent the emergence of resistant strains a variant of the CRISPR/Cas9 technology was developed inducing reactivation or deep latency in latently infected cells
[29]. The method makes use of a defective Cas9 (dCas9) protein fused to virus activators or repressors in view of specific reactivation of latently-infected cells or suppressing HIV-1 expression, respectively [29] [30]. These experiments showed reactivation of HIV expression in CD4 $+\mathrm{T}$ cells and in microglial cell lines [31]. Remarkably, CRISPR/dCas9 when associated with HDAC inhibitors and PKC activators reactivated HIV in a synergistic manner [32].

Despite of considerable progress in new technologies in the field of gene therapy the purge of brain reservoirs (e.g. microglial cells) is still challenging. As evoked above and in [7, 33] HIV-1 brain reservoirs are sanctuaries in which CART does not work efficiently and new technics are needed to overcome limitations.

An original gene therapy has been introduced recently, which relies on the so called suicide gene therapy already well studied in the field of cancer [34, 35]. Indeed, this approach has been used in in vitro experiments to inhibit HIV-1 replication and proved to be safe and effective $[36,37]$. Briefly, expression of the herpes simplex virus thymidine kinase is induced, which in turn converts the prodrug Ganciclovir into a toxic drug followed by apoptosis. We redesigned this strategy in order to specifically target latent brain reservoirs. A recombinant AAV vector including a Long Terminal Repeat-Thymidine kinase (LTR-TK) gene has been developed. The idea was that the reactivated virus produces the trans-activator Tat in latently-infected reservoirs, which in turn drives the expression of the thymidine kinase by binding the HIV-1 promoter LTR. In the presence of the prodrug Ganciclovir, we thus expected to induce apoptosis preferentially in reactivated cells. We used specifically the AAV vector to target latently-infected reservoirs, which is nonpathogenic for human and has the ability to infect both dividing and non-dividing cells [38]. Another advantage is that the vector exhibits stable transgene expression with low risk of insertional mutagenesis [38]. Last but not least, some AAV serotypes have been shown to infect cells in the brain following intravascular administration in preclinical trials $[39,40]$. We show in this paper that a model of latently infected microglial cell when reactivated by Romidepsin and transduced by a recombinant AAV becomes apoptotic.

\section{Materials and methods AAV production Design of the recombinant $A A V$ viral vector}

We designed a Recombinant AAV based vector (rAAV) (Fig. 1) which contains the Herpes Simplex Virus-1 (HSV1) Thymidine Kinase (TK) gene under the control of the HIV-1 promoter LTR (rAAV-LTR-TK). AAV-DJ Helper 

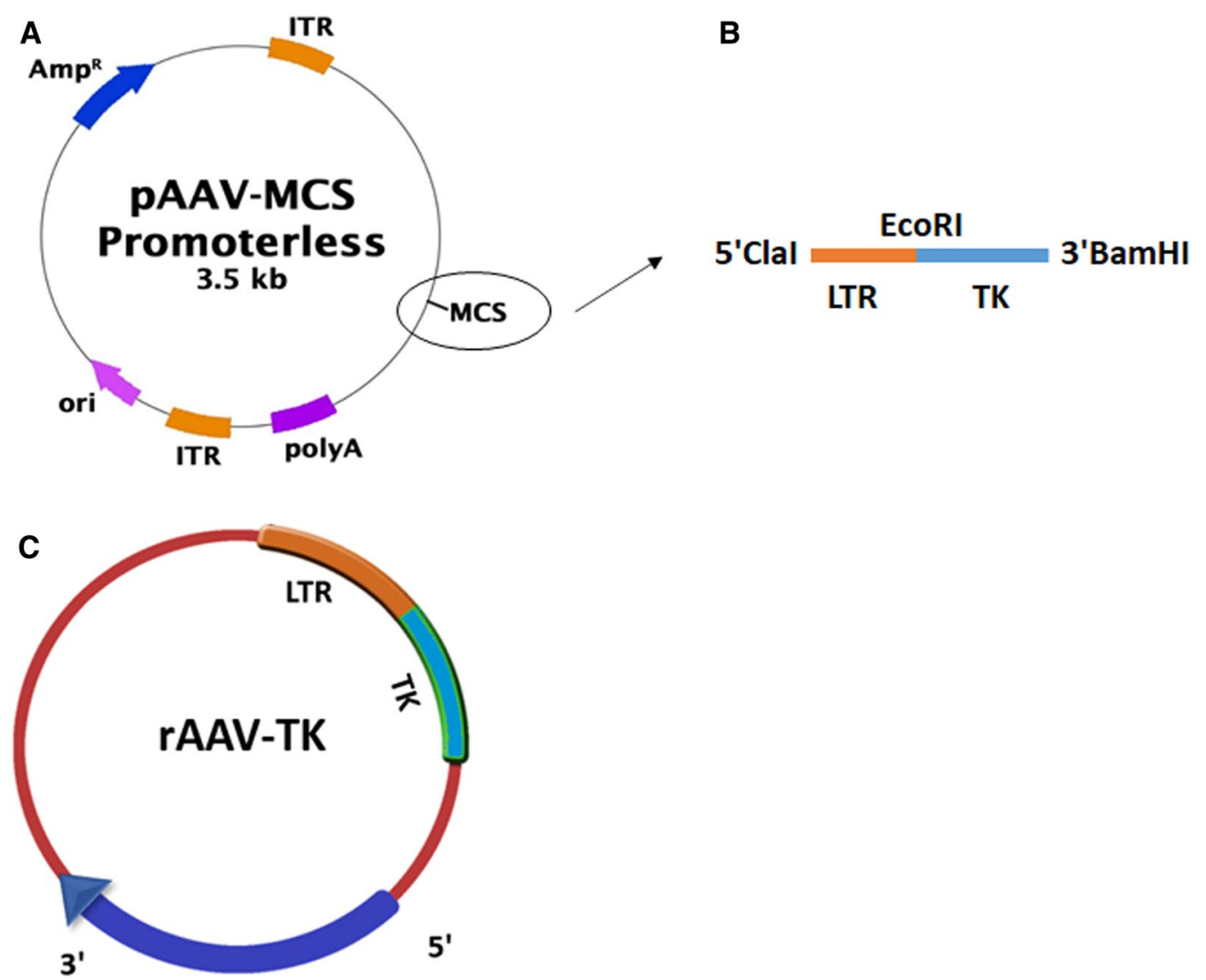

Fig. 1 Cloning strategy for making rAAV-TK vector. HIV-1 LTR sequence was cloned in multiple cloning site of pAAV-MCS promoterless expression vector (a), between Clal and EcoRl restriction enzyme sites. The coding region of TK gene was also incorporated into this vector at the downstream of LTR; between EcoRI and BamHI sites; (b). and rAAV-TK vector was constructed (c)

Free Promoterless Expression System was purchased from CELL BIOLABS (Catalog number: VPK-411-DJ).

The complete sequence of the wild type LTR which contains the TAR structure (ClaI and EcoRI enzyme sites at the 5' and 3' end, respectively) was synthesized. The sequence was obtained from a 2 nd generation lentivector; pLEX-jRED-TurboGFP; (Catalog number: OHS4736). The sequence was cloned into the PUC57 cloning vector, and subcloned into the above mentioned restriction enzyme sites of pAAV-MCS promoterless expression vector.

TK gene cloning was accomplished as follows. HSV-1 TK (Accession number: AB009254.2) was amplified by PCR from a PCDH-CMV-MCS-EF1-Puro (Catalog number: CD510B-1) plasmid carrying the coding region of TK, with primers containing EcoRI site at $5^{\prime}$ and BamHI at 3 ' end. The primers sequences were:

TK Forward primer: 5' CAT CGA TGG AAT TCC TCC GTG TTT CAG TTA GCC 3.

TK Reverse primer: 5' CG GGA TCC CAC CGA GCG ACC CTG 3'.
The PCR product was inserted downstream of the HIV-1 LTR which was cloned before into the pAAV-MCS promoterless expression vector, and the final vector was constructed (rAAV-LTR-TK).

\section{Production of the recombinant AAV LTR-TK virus}

One day before transfection, HEK-293 cells were cultured to achieve $70-80 \%$ confluence. Cotransfection of HEK-293 cells with rAAV-LTR-TK vector, pAAV-DJ and pHelper (with the ratio of 1:1:1 respectively) was achieved by using Calcium Phosphate transfection. 48-72 h after transfection rAAV-LTR-TK viruses were harvested by Freeze/thaw cycles based on the manufacturer instructions. rAAV LTR-TK crude lysate was used directly. rAAV LTR-TK aliquots were stored in $-80{ }^{\circ} \mathrm{C}$. After viral DNA extraction, virus titer was determined by qPCR.

\section{rAAV-LTR-TK transduction}

CHME5/HIV - and CHEM5/HIV + cell lines cultured in DMEM, supplemented with $10 \%$ Fetal Calf serum and $1 \%$ 
penicillin/streptomycin, were plated on 24-well plates. $24 \mathrm{~h}$ later, cells were infected with rAAVs with a titer of 10,000 genome copies / cell (GC/cell). We checked the level of rAAV transduction in both CHME-HIV + and CHME-HIV- cells by qPCR. For this purpose, we performed qPCR to quantify the gene encoding TK which reflects the level of AAV transduced in both CHME5HIV- and CHME5-HIV. The levels of AAV in both cell lines were comparable.

After $24 \mathrm{~h}$ of infection, cells were washed with PBS twice and treated with Romidepsin (Concentration: $0.0175 \mu \mathrm{M})$ to reactivate the latent virus. Next day, Ganciclovir (GCV) was added to the cells at final concentration of $2 \mathrm{mM}$ and $24 \mathrm{~h}$ later, apoptosis assay was done according to "ab219918 Annexin V-iFluor 594 Apoptosis Detection Kit" (Abcam). MTT test for GCV was also performed according to Molecular Probes ${ }^{\mathrm{TM}}$ MTT (3-(4,5-Dimethylthiazol-2-yl)-2,5-Diphenyltetrazolium Bromide) ref: 10,133,722 Fisher Sci. The Percentage of cell reactivation and apoptosis was determined by flow cytometry. For each analysis, at least 5000 events were counted.

We also checked TK expression following Romidepsin treatment in CHME5-HIV + cells transduced with rAAV. We used relative RTqPCR methodology (method of the $\left.-2 \Delta \Delta^{\mathrm{CT}}\right)$. Quantification was normalized with GAPDH.

\section{Statistical analysis}

We performed at least 3 independent experiments for each condition. Data were presented as means and standard deviations (SD). Statistical analysis was performed by GraphPad Prism 9.0.0. Statistical significance was determined using "unpaired t-test with Welch's correction" for comparison between two conditions that do not have equal SDs and "Ordinary one-way ANOVA" to compare 3 or more conditions. $p$ value $<0.05$ was considered statistically relevant and was indicated by stars $(* p<0.05$, "** $p<0.01, * * * * 0.001, * * * * * 0<0.0001)$.

\section{Results}

\section{The suicide gene strategy}

In the experiments recombinant AAV (rAAV) was used to infect CHME5/HIV + cells, a model of latently infected microglial cell line. The rAAV contained the gene coding for the herpes simplex (HS) thymidine kinase and transcription of the vector was driven by the 5 'Long Terminal Repeat (LTR) HIV-1 promoter. Cells expressing the herpes simplex (HS) thymidine kinase (Fig. 2 step 1) were treated with the HDAC inhibitor Romidepsin. In theory Romidepsin induces Tat protein expression by the reactivated virus (Fig. 2 step 2), which in turn activates the synthesis of thymidine kinase (TK) by binding on the LTR-TK promoter. Subsequently cells were treated with the prodrug Ganciclovir. It is awaited that in the presence of TK Ganciclovir is phosphorylated to Ganciclovir triphosphate (Fig. 2 step 3), a toxic form of the drug inducing apoptosis (Fig. 2 step 4). This strategy aims to reactivate specifically latently-infected cells. We expected that only reactivated cells are apoptotic when treated with Ganciclovir.

\section{Transduction of rAAV leads to apoptosis of CHME5/ $\mathrm{HIV}$ + but not that of CHME5/HIV - cells Negative control experiments}

In a first set of experiments, we used as control the nonlatently-infected microglial cell line CHME5 (referred as CHME5/HIV -). The signal level of GFP reflects the percentage of reactivation of latently infected CHME 5 cells (referred as CHME5/HIV+), while the signal level of RFP reflects the percentage of apoptotic cells. As expected, the non-treated and rAAV non-transduced CHME5/HIV - cells were negative for both GFP and RFP (Fig. 3 lane 1 and 2). We next checked whether various treatments by Romidepsin and Ganciclovir do not affect CHME5/HIV - cells transduced or not with rAAV. We showed that in cells transduced with rAAV but not treated with Romidepsin, the percentage of apoptotic cells in the presence or absence of Ganciclovir was low suggesting that the rAAV vector did not induce apoptosis of HIV-cells (Fig. 3 lanes 2 and 3). The percentage of reactivated cells $($ GFP + ) and apoptotic cells (RFP + ) that were not transduced by rAAV but treated with Romidepsin, were also very low supporting the idea that Romidepsin has no effect on its own (Fig. 3 lane 4). The slight increase of reactivated cells $(\mathrm{GFP}+)$ in the presence of Romidepsin or absence of Romidepsin $(\sim 3.5 \%$ and $\sim 1.9 \%$ of GFP + , respectively) might reflect the autofluorescence of Romidepsin. In cells transduced with rAAV and treated with Romidepsin in the presence or absence of Ganciclovir, the signal levels of GFP and RFP (Fig. 3 lanes 5 and 6) were also very low, suggesting that Ganciclovir alone did not affect cell viability. The low level of reactivated CHME5/HIV - cells treated with a combination of drugs (Romidepsin and Ganciclovir) and transduced by rAAV (Fig. 3 lane 6) reflects the non-specific background luminosity. Of note, we might expect transcriptional activation of the TK gene driven by the LTR following Romidepsin treatment which could lead to unexpected apoptosis of non-reservoirs (CHME5 without HIV referred as CHME5/HIV-). However, we did not observe such an off-target effect with Romidepsin. Comparing CHME5/HIV - cells transduced by rAAV with and without Romidepsin treatment we notice that the level of apoptotic cells (RFP + ) is low, which could reflect non- specific background luminosity (Fig. 3 lane 3 versus lane 6). 


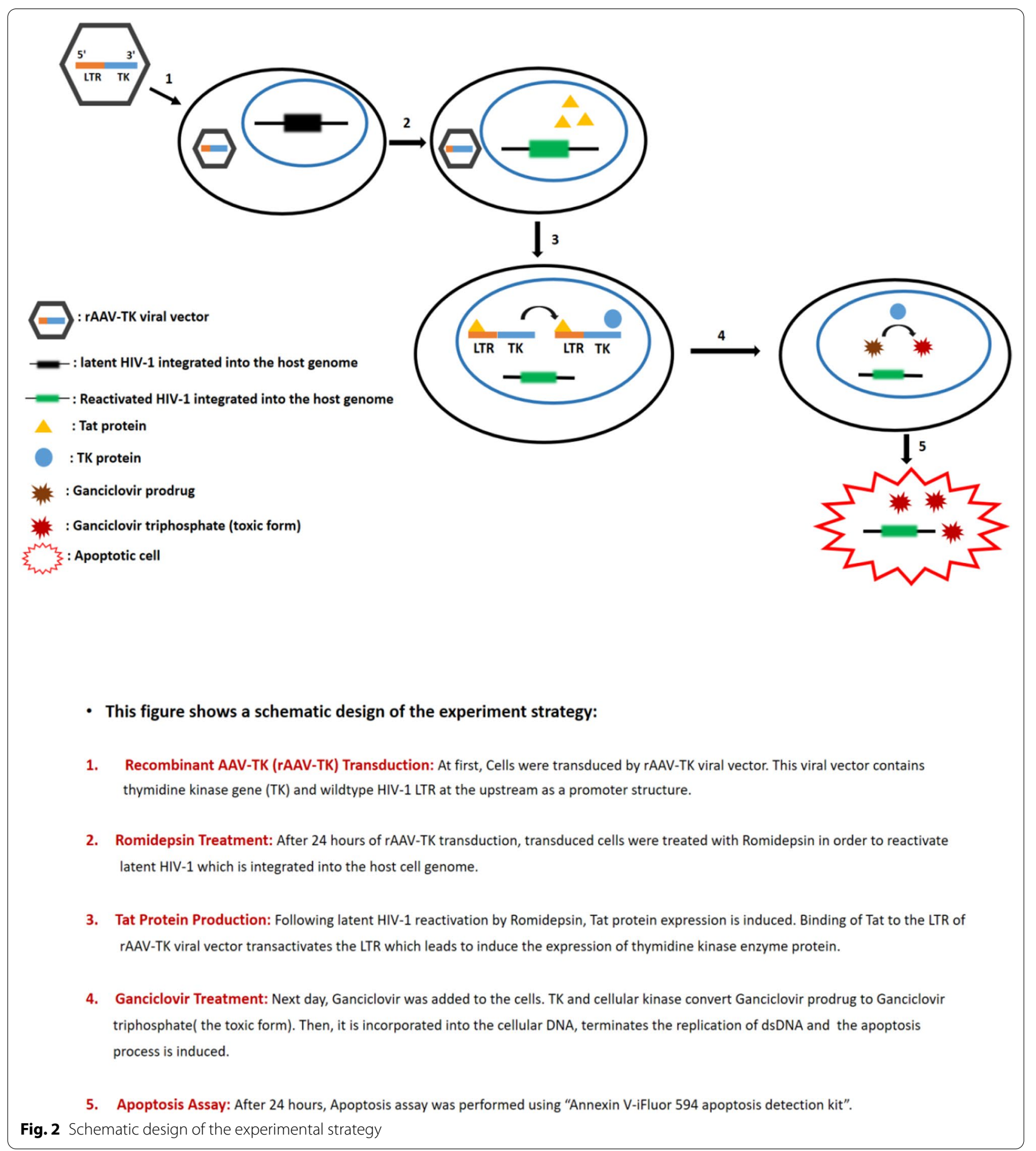

\section{Experiments using the latently-infected microglial cell line CHME5/HIV +}

We next used the latently-infected microglial cell line CHME5/HIV + as a model and applied the same protocol as for the control CHME5/HIV - experiments (Fig. 4). We monitored the expression of GFP ( $\mathrm{Y}$ axis) which reflects the percentage of reactivated CHME $5 / \mathrm{HIV}+$ cells and the expression of RFP (X axis) which reflects the percentage of apoptotic cells. Representative dot plots of cell gates shows reactivated CHME5/HIV + cells (upper right and left quadrant) and apoptotic cells (upper and down right quadrant) (Fig. 4b). We visualized reactivated 


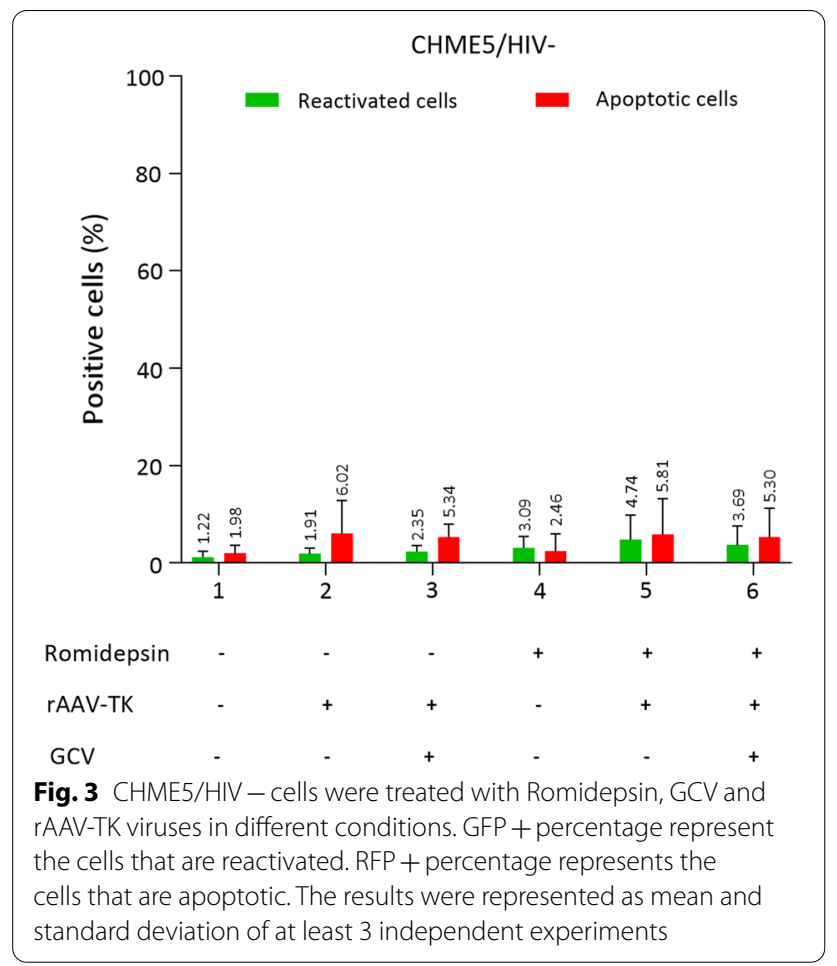

cells $(\mathrm{GFP}+)$ following Romidepsin treatment on the $\mathrm{Y}$ axis (compare right and left representation of the dot plots figure B). Interestingly, we only observe apoptotic cells (RFP +) among CHME5/HIV + cells transduced with rAAV-TK and treated with Romidepsin and Ganciclovir ((Fig. 4b compare the bottom right and left representations of the dot plots). We observed around 40\% reactivation of CHME5/HIV + cells following Romidepsin treatment in the presence or absence of Ganciclovir (Fig. 4 lanes 4, 5 and 6). On the other hand, in the absence of Romidepsin, reactivation of CHME $5 / \mathrm{HIV}+$ is low and comparable to the non-specific background observed with CHME5/HIV - cells (compare Fig. 4 lane 2 and 3 with Fig. 3 lane 2 and 3). Around 22\% of the cells are apoptotic (RFP +) in the presence of Ganciclovir (Fig. 4 lane 6). In CHME5/HIV + cells transduced with rAAVTK and treated with Ganciclovir we still observe some GFP + cells when treated with Romidepsin but subsequently they become RFP + that is apoptotic. The level of reactivation following Romidepsin treatment is comparable in CHME5/HIV + cells not transduced or transduced with rAAV (around 35 to 40\%) (Fig. 4 lane 4 versus lanes 5 and 6). Interestingly, in cells not transduced with rAAV but treated with Romidepsin, the level of apoptotic cells $(\mathrm{RFP}+)$ was very low with a similar background level of

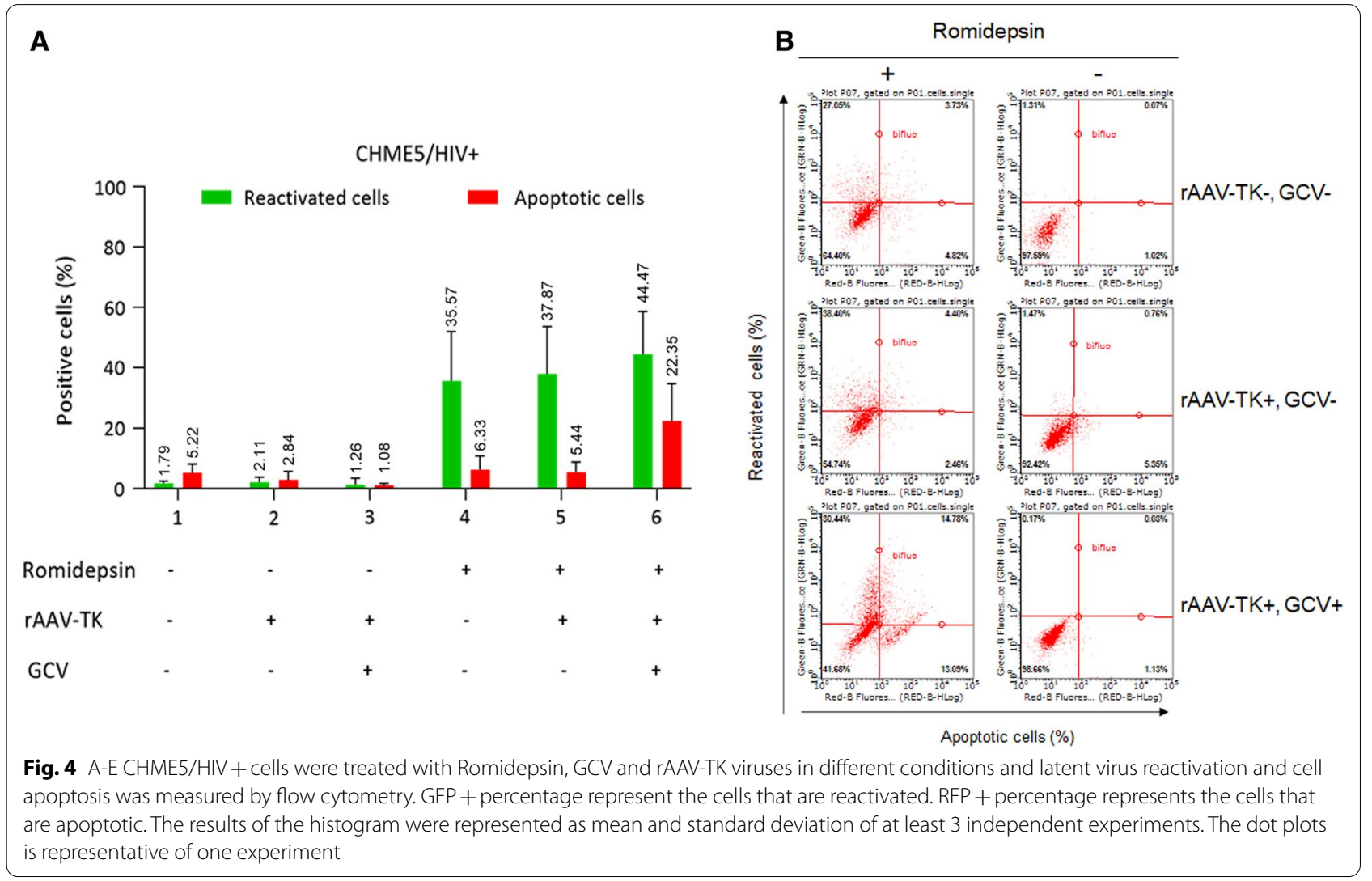


fluorescence as observed in CHME5/HIV - cells (compare Fig. 4 lane 4 with Fig. 3 lane 4). Finally, CHME5/ HIV + cells transduced with rAAV and treated with Ganciclovir needed to be reactivated by Romidepsin to generate fluorescence (GFP + and RFP + ) (Fig. 4 lane 3 versus 6).

A synthesis of our results is shown in Fig. 5.In the figure the effects of the various treatments on CHME5/ HIV + and CHME5/HIV - cells are compared. The figure demonstrates well that cells reactivated by Romidepsin were exclusively CHME5/HIV + cells (GFP + lane 1 and 2 ) and only cells treated with Ganciclovir were apoptotic (RFP + lane 3 versus 4).

\section{Discussion}

There is now numerous evidence suggesting that the major cellular reservoir of HIV-1 in the brain are microglial cells $[7,33]$. These cells are believed to be the source of peripheral tissues reseedings and responsible for the emergence of drug resistance. Moreover, these lifelong reservoirs are known to be responsible for the development of HIV-1 associated neurocognitive diseases (HAND). Microglial cells differentiate from the myeloid precursors of the embryogenic yolk sac at a very early stage of embryogenesis [41, 42]. They colonize the entire brain parenchyma before the formation of the Brain Blood Barrier and form a slowly dividing population of cells in the brain [41]. In a recent study, the average age of microglial cells was evaluated to 4.2 years and the great majority of them were shown to be capable of cell division all along their life-time [43]. This means that infected microglial cells make brain infection permanent contrary to other infected cells found in the brain.

Targeting these cells located in anatomic and pharmacologic sanctuaries is however very challenging [7]. In the classic "Shock and Kill" strategy latently-infected $\mathrm{T}$ CD $4+$ cells are first reactivated by the Shock strategy and the newly formed viruses are eliminated by cART. On the other hand, reactivated HIV-1 positive cells are eliminated by the Kill strategy. A main backlash of the Kill strategy is that it is unable to eradicate all reservoirs despite latent cells becoming productive following reactivation. The failure is essentially due to the complexity of the Kill strategy, which does not allow direct elimination of reactivated cells. An original way to circumvent this problem is to use the suicide gene therapy. A major advantage of the strategy is that it eliminates reactivated cells directly and specifically by apoptosis. Thus in case of microglial cells neurotoxic viral proteins such as Tat and $\mathrm{Vpr}$ are not produced neither released. This could be a major improvement compared to the classical Kill strategy which has no effect on viral transcription even when enhanced cART is applied. Although much efforts have been employed to discover new molecules inhibiting the transcriptional step no drugs has been put on the market to date [4].

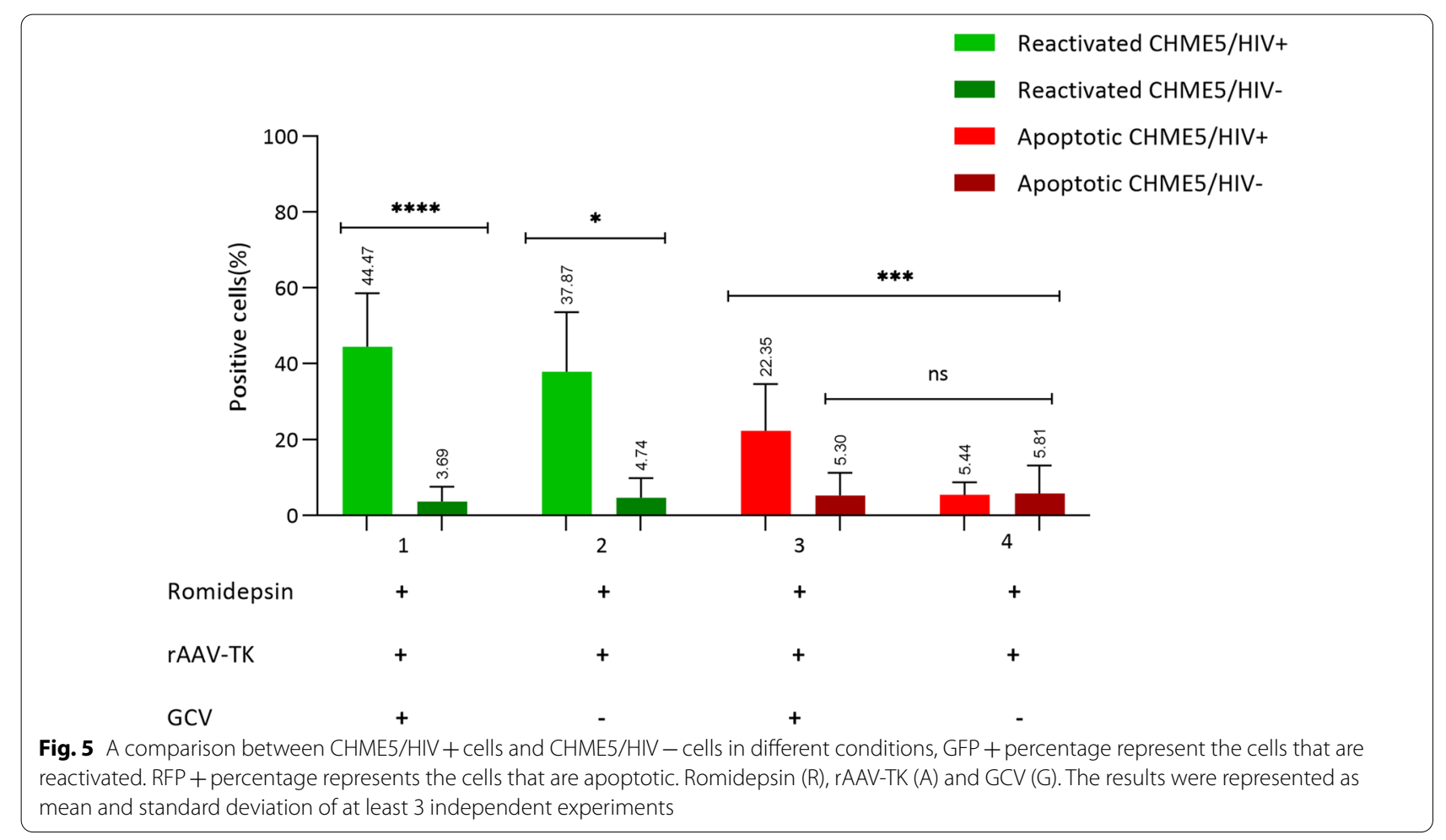


Here we have set up a gene suicide strategy using a latently infected microglial model. We used the potent HDAC inhibitor Romidepsin to reactivate latentlyinfected microglial cells. HDAC contributes to the transcriptional silencing of HIV-1 by inducing heterochromatin formation. First we showed that Romidepsin is able to reverse specifically heterochromatin silencing of the virus. Next we demonstrated that Ganciclovir treatment induces apoptosis of Romidepsin activated recombinant cells. Control cells, which were not transduced with rAAV were unaffected by treatments. Remarkably, only reactivated cells became apoptotic. These results strongly support the concept that the suicide gene strategy allows the specific elimination of latently infected cells.

It is noteworthy that Romidepsin treatment does not allow complete reactivation of latently infected cells. As in other strategies aiming to reactivate latent reservoirs, a combination of LRAs chosen from an existing pool of 160 LRA drugs should improve the level of reactivation [44, 45].

Although gene therapies show huge promises, they still need to be improved to achieve functional cure. Two main directions should be investigated: (i) designing efficient LRAs for the CNS and (ii) improving delivery of HIV drugs into the CNS and into the various CNS cells.

Several HDAC inhibitors (HDACi) have been tested in primary cells (astrocytes and macrophages) [46, 47]. Preliminary data showed that some LRAs including panobinostat [48] and JQ1 [49] are relatively nontoxic and are able to trigger HIV reactivation at a therapeutic concentration [47]. Bryostatin-1, an LRA drug which activates Protein Kinase $\mathrm{C}$ and crosses the blood brain barrier could be exploited in the suicide gene strategy especially if designed for microglial cells [50, 51].

Improvement of both the bioavailability and the biodistribution of LRAs is also awaited with the development of carriers such as liposomes, dendrimers and micelles. Adeno-associated viruses are good candidates for delivering transgenes such as the LTR-TK transgene and/or drugs into the brain. Among the many serotypes tested AAV9 and AAV8 were shown to cross the BBB, which makes intravascular administration of the vectors feasible [52]. In primary human brain microvascular endothelial cells used as a model of human BBB, AAV9 was shown to cross the BBB and transduce brain cells following systemic administration [53]. rAAV9 was further tested in a clinical trial to treat neurological disorders [54]. However, gene transfer with rAAV9 was less effective in the adult than in the neonatal brain. A recent study found that systemic administration of an AAV8 mutant resulted in a more widespread brain gene transfer than that of rAAV9. Moreover, the study showed that BBB shuttle peptides improved AAV transduction in the brain [55].

\section{Conclusion}

In conclusion, we provided proof of concept of the gene suicide strategy in this paper. Our results demonstrate that this strategy enables the eradication of latentlyinfected microglial cells. We expect that suicide gene therapy could be applied successfully in in vivo. This strategy could efficiently target latently-infected microglial cells in the brain, reactivating these cells by LRAs followed by their apoptosis. This approach thus prevents inflammation and the release of viral neurotoxic proteins which are secondary to reactivation. Indeed, the suicide gene approach aims to kill reactivated infected cells and simultaneously inhibit the release of new particles and viral products. The ultimate purge or at least considerable reduction of brain reservoirs, especially of microglial cells, is conceivable.

\begin{abstract}
Abbreviations
AAV: Adeno associated virus; BBB: Blood brain barrier; CART: Combination antiretroviral therapy; CNS: Central nervous system; CD4: Cluster of differentiation 4; CTLs: Cytotoxic T cells; CTIP2: COUP-Tf interacting protein 2; CCR5: Chemokine receptor type 5; CHME5/HIV_: Non-latently-infected microglial cell line; CHME5/HIV+: HIV-1 latently-infected microglial cell line; dCA: Didehydro-corticostatin; GCV: Ganciclovir; GFP: Green fluorescent protein; gp120: Glycoprotein 120; HAND: HIV-1 associated neurocognitive diseases; HIV-1: Human immunodeficiency virus 1; HDAC: Histone deacetylase; HSV: Herpes simplex virus; LRAs: Latency-reversing agents; LPAs: Latency-promoting agents; LSD1: Lysine-specific histone demethylase 1; LTR: Long terminal repeat; PKC: Protein kinase C; P-TEFb: Positive transcription elongation factor; RFP: Red fluorescent protein; SUV39H1: Suppressor of Variegation 3-9 Homolog 1; TK: Thymidine kinase.
\end{abstract}

\section{Acknowledgements}

We are grateful to Andrea Janossy for careful and critical reading of the manuscript.

\section{Authors' contributions}

SS performed all the experiments. SS, MR, MRP and KB designed the gene suicide TK vector and revised the manuscript. SS, CW and FD made the acquisition of the data. CW, OR, MR and CS interpreted the data. CW and SS designed the figures. CW and OR revised the manuscript. CW and CS designed the experiments. CS drafted the work.

\section{Funding}

This work in OR and CS laboratory was supported by grants from the French agency for research on AIDS and viral hepatitis (ARNS), Sidaction, the European Union's Horizon 2020 research and innovation program under grant agreement No. 691119_EU4HIVCURE_H2020-MSCA-RISE-2015, Alsace contre le Cancer and Institut Universitaire de France. The research work of SS was conducted as a PhD dissertation and supported by Dean of research and technology, Tarbiat Modares University.

Availability of data and material

Contact the corresponding authors Christian Schwartz or Mehrdad Ravanshad. 


\section{Declarations}

Ethics approval and consent to participate

Not applicable.

\section{Consent to publication}

Not applicable.

\section{Competing interests}

The authors declare that they have no competing interests.

\section{Author details}

${ }^{1}$ Department of Virology, Faculty of Medical Sciences, Tarbiat Modares University, Tehran, Iran. ${ }^{2}$ University of Strasbourg, Research Unit 7292, DHPI, IUT Louis Pasteur, Schiltigheim, France. ${ }^{3} \mathrm{KU}$ Leuven, Department of Microbiology, Immunology and Transplantation, Division of Clinical and Epidemiological Virology, 3000 Leuven, Belgium. ${ }^{4}$ Hepatitis and AIDS Department, Pasteur Institute of Iran, Tehran, Iran.

Received: 22 June 2020 Accepted: 21 May 2021

Published online: 31 May 2021

\section{References}

1. García M, Buzón MJ, Benito JM, Rallón N. Peering into the HIV reservoir. Rev Med Virol. 2018;28:e1981.

2. Sung JM, Margolis DM. HIV Persistence on Antiretroviral Therapy and Barriers to a Cure. Adv Exp Med Biol. 2018. p. 165-85.

3. Marcello A. Latency: the hidden HIV-1 challenge. Retrovirology. 2006;3:7

4. Le Douce V, Ait-Amar A, Forouzan Far F, Fahmi F, Quiel J, El Mekdad H, et al. Improving combination antiretroviral therapy by targeting HIV-1 gene transcription. Expert Opin Ther Targets. 2016;20:1311-24.

5. Le Douce V, Cherrier T, Riclet R, Rohr O, Schwartz C. The many lives of CTIP2: from AIDS to cancer and cardiac hypertrophy. J Cell Physiol. 2014;229:533-7.

6. Le Douce V, Forouzanfar F, Eilebrecht S, Van Driessche B, Ait-Ammar A, Verdikt R, et al. HIC1 controls cellular- and HIV-1- gene transcription via interactions with CTIP2 and HMGA1. Sci Rep. 2016:6:34920.

7. Marban C, Forouzanfar F, Ait-Ammar A, Fahmi F, El Mekdad H, Daouad F, et al. Targeting the brain reservoirs: toward an HIV cure. Front Immunol. 2016;7:397.

8. Cherrier T, Suzanne S, Redel L, Calao M, Marban C, Samah B, et al. p21(WAF1) gene promoter is epigenetically silenced by CTIP2 and SUV39H1. Oncogene. 2009;28:3380-9. https://doi.org/10.1038/onc.2009 193.

9. Le Douce V, Colin L, Redel L, Cherrier T, Herbein G, Aunis D, et al. LSD1 cooperates with CTIP2 to promote HIV-1 transcriptional silencing. Nucl Acids Res. 2012;40:1904-15.

10. Marban C, Suzanne S, Dequiedt F, de Walque S, Redel L, Van Lint C, et al. Recruitment of chromatin-modifying enzymes by CTIP2 promotes HIV-1 transcriptional silencing. Embo J. 2007;26:412-23.

11. Cherrier T, Le Douce V, Eilebrecht S, Riclet R, Marban C, Dequiedt F, et al. CTIP2 is a negative regulator of P-TEFb. Proc Natl Acad Sci. 2013;110:12655-60.

12. Eilebrecht $S$, Le Douce V, Riclet R, Targat B, Hallay H, Van Driessche B, et al. HMGA1 recruits CTIP2-repressed P-TEFb to the HIV-1 and cellular target promoters. Nucl Acids Res. 2014;42:4962-71.

13. Schwartz C, Bouchat S, Marban C, Gautier V, Van Lint C, Rohr O, et al. On the way to find a cure: Purging latent HIV-1 reservoirs. Biochem Pharmacol. 2017:146:10-22.

14. Eisfeld C, Reichelt D, Evers S, Husstedt I. CSF penetration by antiretroviral drugs. CNS Drugs. 2013;27:31-55.

15. Watters SA, Mlcochova P, Gupta RK. Macrophages: the neglected barrier to eradication. Curr Opin Infect Dis. 2013;26:561-6.

16. Nath A, Clements JE. Eradication of HIV from the brain: reasons for pause. AIDS. 2011. p. 577-80.

17. Yadav A, Collman RG. CNS inflammation and macrophage/microglial biology associated with HIV-1 infection. J Neuroimmune Pharmacol. 2009;4:430-47.
18. Darcis G, Van Driessche B, Van Lint C. HIV Latency: Should We Shock or Lock? Trends Immunol. 2017;38:217-28.

19. Elsheikh MM, Tang Y, Li D, Jiang G. Deep latency: A new insight into a functional HIV cure. EBioMedicine. 2019.

20. Mousseau G, Aneja R, Clementz MA, Mediouni S, Lima NS, Haregot A, et al. Resistance to the tat inhibitor didehydro-cortistatin a is mediated by heightened basal HIV-1 transcription. MBio. Am Soc Microbiol; 2019;10.

21. Check Hayden E. Stem-cell transplants may purge HIV. Nature. Springer Science and Business Media LLC; 2013 [cited 2021 Apr 14].

22. Xiao Q, Guo D, Chen S. Application of CRISPR/Cas9-based gene editing in HIV-1/AIDS therapy. Front. Cell. Infect. Microbiol. Frontiers Media S.A 2019.

23. Yee J-K. Off-target effects of engineered nucleases. FEBS J. 2016;283:3239-48.

24. Kaminski R, Bella R, Yin C, Otte J, Ferrante P, Gendelman HE, et al. Excision of HIV-1 DNA by gene editing: a proof-of-concept in vivo study. Gene Ther Nature Publish Group. 2016:23:690-5.

25. Yoder KE, Bundschuh R. Host double strand break repair generates HIV-1 strains resistant to CRISPR/Cas9. Sci Rep. 2016:6:29530.

26. Liang C, Wainberg MA, Das AT, Berkhout B. CRISPR/Cas9: a doubleedged sword when used to combat HIV infection. Retrovirology. 2016;13:37.

27. Wang Z, Pan Q, Gendron P, Zhu W, Guo F, Cen S, et al. CRISPR/Cas9derived mutations both inhibit HIV-1 replication and accelerate viral escape. Cell Rep. 2016;15:481-9.

28. Wang G, Zhao N, Berkhout B, Das AT. CRISPR-Cas9 can inhibit HIV-1 replication but NHEJ repair facilitates virus escape. Mol Ther. 2016;24:522-6.

29. Wang G, Zhao N, Berkhout B, Das AT. CRISPR-Cas based antiviral strategies against HIV-1. Virus Res. 2018;244:321-32.

30. Zhang Y, Yin C, Zhang T, Li F, Yang W, Kaminski R, et al. CRISPR/gRNAdirected synergistic activation mediator (SAM) induces specific, persistent and robust reactivation of the HIV-1 latent reservoirs. Sci Rep. 2015;5:16277.

31. Cary DC, Matija Peterlin B. Open Peer Review. 2016

32. Limsirichai $P, G a j T$, Schaffer DV. CRISPR-mediated activation of latent HIV-1 expression. Mol Ther. 2016;24:499-507.

33. Wallet C, De Rovere M, Van Assche J, Daouad F, De Wit S, Gautier V, et al. Microglial Cells: The Main HIV-1 Reservoir in the Brain. Front. Cell. Infect. Microbiol. Frontiers Media S.A.; 2019.

34. Düzgüneş N. Origins of suicide gene therapy. Methods Mol Biol. Humana Press Inc.: 2019. p. 1-9.

35. Düzgüneş $\mathrm{N}$, Konopka K. Eradication of human immunodeficiency virus type-1 (HIV-1)-infected cells. Pharmaceutics. MDPI AG; 2019.

36. Huelsmann PM, Hofmann AD, Knoepfel SA, Popp J, Rauch P, Di Giallonardo $F$, et al. A suicide gene approach using the human pro-apoptotic protein tBid inhibits HIV-1 replication. BMC Biotechnol; 2011;11.

37. Garg H, Joshi A. Conditional cytotoxic anti-HIV gene therapy for selectable cell modification. Hum Gene Ther. 2016:27:400-15.

38. Pattali R, Mou Y, Li XJ. AAV9 Vector: a Novel modality in gene therapy for spinal muscular atrophy. Gene Ther. Nature Publishing Group; 2019. p. 287-95.

39. Duan D. Systemic delivery of adeno-associated viral vectors. Curr. Opin Virol. Elsevier B.V.; 2016. p. 16-25.

40. Lykken EA, Shyng C, Edwards RJ, Rozenberg A, Gray SJ. Recent progress and considerations for AAV gene therapies targeting the central nervous system. J. Neurodev. Disord. BioMed Central Ltd.; 2018.

41. Gomez Perdiguero E, Klapproth K, Schulz C, Busch K, Azzoni E, Crozet $L$, et al. Tissue-resident macrophages originate from yolk-sac-derived erythro-myeloid progenitors. Nature. 2015;518:547-51.

42. Sheng J, Ruedl C, Karjalainen K. Most tissue-resident macrophages except microglia are derived from fetal hematopoietic stem cells. Immunity. 2015;43:382-93.

43. Réu P, Khosravi A, Bernard S, Mold JE, Salehpour M, Alkass K, et al. The lifespan and turnover of microglia in the human brain. Cell Rep. 2017:20:779-84.

44. Abner E, Jordan A. HIV "shock and kill" therapy: in need of revision. Antiviral Res. 2019;166:19-34

45. Ait-Ammar A*, Kula A*, Darcis G, Verdikt R, De Wit S, Gautier V, Mallon PWG, Marcello A RO and VLC (* ${ }^{*}$ equal contribution). Current status of LRAs facing the heterogeneity of HIV-1 cellular and tissue reservoirs. 
46. Chauhan A. Enigma of HIV-1 latent infection in astrocytes: an in-vitro study using protein kinase $C$ agonist as a latency reversing agent. Microbes Infect. 2015;17:651-9.

47. Gray LR, On H, Roberts E, Lu HK, Moso MA, Raison JA, et al. Toxicity and in vitro activity of HIV-1 latency-reversing agents in primary CNS cells. J Neurovirol. 2016.

48. Rasmussen TA, Schmeltz Søgaard O, Brinkmann C, Wightman F, Lewin SR, Melchjorsen J, et al. Comparison of HDAC inhibitors in clinical development: effect on HIV production in latently infected cells and T-cell activation. Hum Vaccin Immunother. 2013;9:993-1001.

49. Banerjee C, Archin N, Michaels D, Belkina AC, Denis GV, Bradner J, et al. BET bromodomain inhibition as a novel strategy for reactivation of HIV-1. J Leukoc Biol. 2012;92:1147-54.

50. Díaz L, Martínez-Bonet M, Sánchez J, Fernández-Pineda A, Jiménez JL, Muñoz E, et al. Bryostatin activates HIV-1 latent expression in human astrocytes through a PKC and NF-kB-dependent mechanism. Sci Rep. 2015;5:12442

51. Darcis G, Kula A, Bouchat S, Fujinaga K, Corazza F, Ait-Ammar A, et al. An in-depth comparison of latency-reversing agent combinations in various in vitro and ex vivo HIV-1 latency models identified bryostatin-1+JQ1 and ingenol-B+JQ1 to potently reactivate viral gene expression. PLoS Pathog. 2015;11:e1005063. https://doi.org/10.1371/journal.ppat.1005063.

52. Saraiva J, Nobre RJ, Pereira de Almeida L. Gene therapy for the CNS using AAVs: The impact of systemic delivery by AAV9. J. Control. Release. Elsevier B.V.; 2016. p. 94-109.

53. Merkel SF, Andrews AM, Lutton EM, Mu D, Hudry E, Hyman BT, et al. Trafficking of adeno-associated virus vectors across a model of the bloodbrain barrier; a comparative study of transcytosis and transduction using primary human brain endothelial cells. J Neurochem. 2017;140:216-30.

54. Wirth B, Barkats M, Martinat C, Sendtner M, Gillingwater TH. Moving towards treatments for spinal muscular atrophy: Hopes and limits. Expert Opin. Emerg. Drugs. Taylor and Francis Ltd; 2015. p. 353-6.

55. Zhang X, He T, Chai Z, Samulski RJ, Li C. Blood-brain barrier shuttle peptides enhance AAV transduction in the brain after systemic administration. Biomaterials. 2018;176:71-83.

\section{Publisher's Note}

Springer Nature remains neutral with regard to jurisdictional claims in published maps and institutional affiliations.
Ready to submit your research? Choose BMC and benefit from:

- fast, convenient online submission

- thorough peer review by experienced researchers in your field

- rapid publication on acceptance

- support for research data, including large and complex data types

- gold Open Access which fosters wider collaboration and increased citations

- maximum visibility for your research: over $100 \mathrm{M}$ website views per year

At BMC, research is always in progress.

Learn more biomedcentral.com/submissions 